\title{
Sepsis-Induced Diabetic Ketoacidosis (DKA) in Latent Autoimmune Diabetes in Adult (LADA)
}

\section{Fadel Fikri Suharto ${ }^{*}$, Alwi Shahab², Yulianto Kusnadi², RM Dewi Anggraini2}

${ }^{1}$ Department of Internal Medicine, Faculty of Medicine, Universitas Sriwijaya, Palembang, Indonesia

2 Endocrine Metabolic and Diabetes Division, Department of Internal Medicine, Faculty of Medicine, Universitas Sriwijaya, Palembang, Indonesia

\section{A R T I C L E I N F O}

Keywords:

Autoimmune disease

Diabetes mellitus

Urinary tract infection

Ketoacidosis diabetic

Sepsis

*Corresponding author:

Fadel Fikri Suharto

E-mail address:

fadel.humas.ismki@gmail.com

All authors have reviewed and approved the final version of the manuscript.

\section{https://doi.org/10.37275/bsm.v6i2.452}

\begin{abstract}
A B S T R A C T
Backgrounds: Latent autoimmune diabetes in adults (LADA) is a slowly progressive form of autoimmune diabetes mellitus characterized by older age at diagnosis, presence of pancreatic autoantibodies, and lack of absolute insulin requirement at diagnosis. Patients with LADA had better $\beta$-cell function than patients with classic Type $1 \mathrm{DM}$ (T1DM). Over time, LADA tends to experience rapid and progressive loss of beta-cell function that requires intensive insulin therapy. This case report aims to describe a case of Diabetic Ketoacidosis (DKA) in a patient with latent autoimmune diabetes in adult (LADA) induced by sepsis (urinary tract infection/UTI).

Case Presentations: A woman, 28 years old, came to the Emergency Department (ED) RSMH Palembang with chief complaints of decreased consciousness and shortness of breath. The patient had a history of frequent urination, pain when urinating, and fever. Urinalysis examinations were glycosuria, proteinuria, hematuria. Hb-A1c level was 10.7\%, C-Peptide 0.11 ng/dL, Anti GAD65 qualitative positive, and islet cell antibody (ICA) negative. The patient was diagnosed with diabetic ketoacidosis (DKA), LADA, and sepsis due to urinary tract infection (UTI). Patients were managed with DKA and sepsis management algorithms.

Conclusion: Diabetic ketoacidosis (DKA) in LADA caused by sepsis is an emergency in the metabolic endocrine and diabetes fields. Prompt and appropriate management can improve outcome prognosis in this case.
\end{abstract}

\section{Introduction}

Diabetes mellitus (DM) is a group of metabolic diseases characterized by hyperglycemia that occurs due to defects in insulin secretion, insulin action, or both. Among degenerative diseases, diabetes is one of the non-communicable diseases that will increase in number in the future. World Health Organization (WHO) estimates that in 2000 the number of people with diabetes over the age of 20 years amounted to 150 million people and within 25 years it will increase to 300 million people. ${ }^{1}$

Latent autoimmune diabetes in adults (LADA) is a slowly progressive form of autoimmune diabetes mellitus characterized by an older age at diagnosis, the presence of pancreatic autoantibodies, and a lack of absolute insulin requirement at diagnosis. Patients with LADA experience better $\beta$-cell function disorders than patients with classic type 1 DM (T1DM). Over time, LADA tends to experience rapid and progressive loss of beta-cell function that requires intensive insulin therapy. ${ }^{2}$

Diabetic ketoacidosis (DKA) is a decompensated state of metabolic derangement characterized by the triad of hyperglycemia, acidosis, and ketosis, mainly due to absolute or relative insulin deficiency. Diabetic 
ketoacidosis (DKA) is characterized by laboratory examinations of serum glucose levels exceeding 250 $\mathrm{mg} / \mathrm{dL}$, pH less than 7.3, serum bicarbonate levels less than $18 \mathrm{mEq} \mathrm{L}$, elevated serum ketone levels, and dehydration. Insulin deficiency is the main precipitating factor for this condition. Common symptoms include polyuria with polydipsia (98\%), weight loss $(81 \%)$, fatigue $(62 \%)$, shortness of breath $(57 \%)$, vomiting $(46 \%)$, previous history of fever $(40 \%)$, abdominal pain $(32 \%)$, and polyphagia $(23 \%)$. Appropriate management, in this case, is the administration of intravenous fluids and insulin, and monitoring of glucose and electrolyte levels. ${ }^{3}$

\section{Case Presentation}

A woman, 28 years old, came to the Emergency Department (ED) RSMH Palembang with chief complaints of decreased consciousness and shortness of breath. No history of headaches and seizures. History of trias DM (polydipsia, polyuria, polyphagia) and weight loss since 1 month ago. History of dysuria and fever since 1 week ago. On physical examination, the patient was apathy, blood pressure $130 / 80 \mathrm{mmHg}$, pulse $110 \mathrm{x} / \mathrm{m}$, respiratory rate $28 \mathrm{x} / \mathrm{m}$, with Kussmaul breathing pattern, temperature $37.5^{\circ} \mathrm{C}$, BMI 27.3 $\mathrm{kg} / \mathrm{m}^{2}$, abdominal circumference $98 \mathrm{~cm}$, upper arm circumference $33 \mathrm{~cm}$.

Laboratory examinations were Haemoglobin 14.3 g/dL, Leukocytes 29,000 $\mu \mathrm{L}$, Platelet 454,000 $\mu \mathrm{L}$, blood glucose $636 \mathrm{mg} / \mathrm{dL}$, ureum 46mg/dL, creatinine
$2.52 \mathrm{mg} / \mathrm{dL}$, blood gas analysis $\mathrm{pH}$ 7.061, PCO2 17.0 $\mathrm{mmHg}$, HCO3 $4.9 \mathrm{mmol} / \mathrm{L}$, PO2/FiO2 $84.1 \mathrm{mmHg}$, Anion gap $31.8 \mathrm{mmol} / \mathrm{L}$, Quantitative CRP $85.7 \mathrm{mg} / \mathrm{L}$. Urinalysis examination were proteinuria, glycosuria, bacteriuria, ketonuria, urine culture showed Candida tropicalis and sensitive to mycafungin $(<0.05)$. HbA1c 10.7 with C-peptide $0.11 \mathrm{ng} / \mathrm{mL}$. Qualitative Anti GAD65 antibody positive and islet cell antibody (ICA) negative.

Patients were managed with rehydration of $0.9 \%$ saline solution, drip insulin aspart, administration of sodium bicarbonate preparations, antibiotic meropenem 2x1gr, antifungal mycafungin 1x50mg, fluconazole 2x150mg.

\section{Discussion}

Latent autoimmune diabetes in adults (LADA) is a condition in which islet antibodies are present in patients with diabetes mellitus, a course of a slow $\beta$ cell autoimmune process. Therefore, LADA patients do not require insulin, for at least the first 6 months after the diagnosis of diabetes mellitus. Among patients with phenotypic type 2 diabetes mellitus, LADA occurs in $10 \%$ of individuals older than 35 years and in $25 \%$ under that age. Prospective cell function studies showed that LADA patients with multiple islet antibodies developed cell failure within 5 years, whereas those with only GAD antibodies (GADA) or only islet cell antibodies (ICA) had a large proportion of $\beta$ cell dysfunction after 5 years. 5

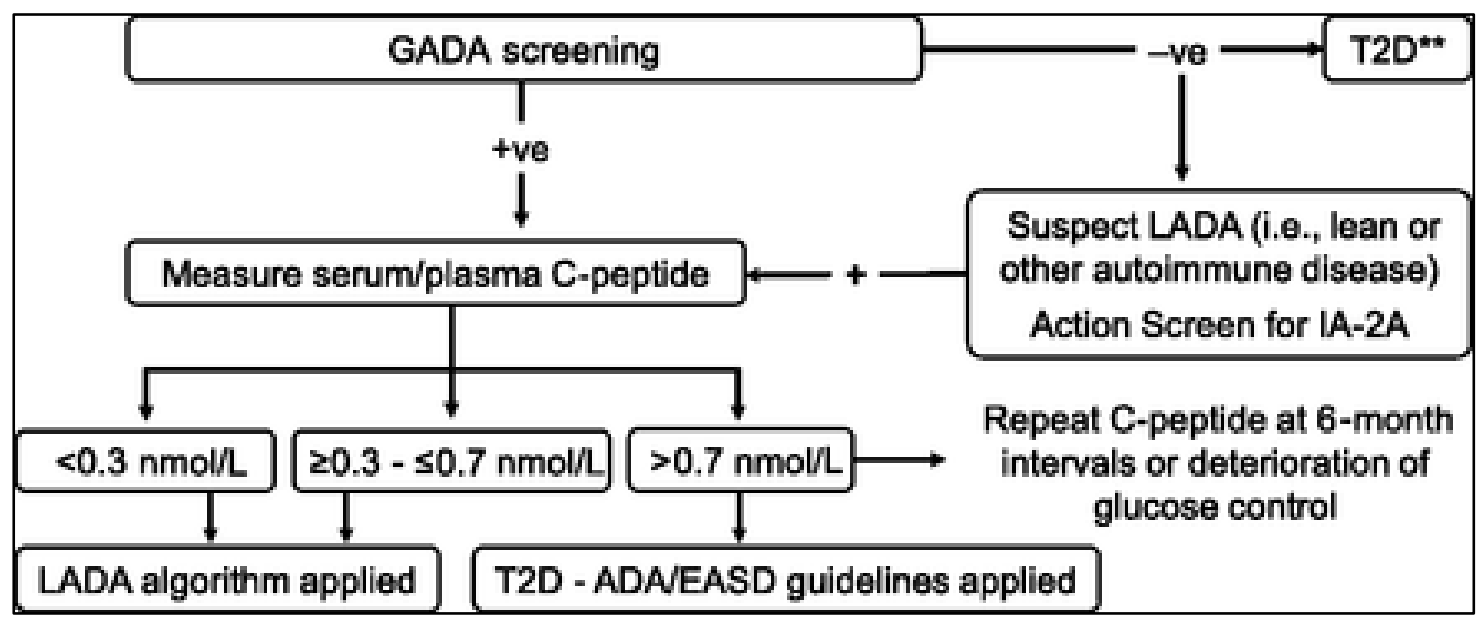

Figure 1. LADA diagnosis algorithm ${ }^{5}$ 
In this case, 28 years-old women came with complaints of decreased consciousness and short of breath since 1 day ago, the recent history of polydipsia, polyuria, especially at night, weight loss, following classic complaints of DM. Blood sugar was $636 \mathrm{mg} / \mathrm{dL}$ in ER. Hb-A1c examination was performed and the result was $10.7 \%$. Accordance with criteria for the diagnosis of DM, blood sugar > 200mg/dL with classic complaints and $\mathrm{Hb}-\mathrm{A} 1 \mathrm{c}>6.5 \% .4,5,13$.
C-Peptide was $0.11 \mathrm{ng} / \mathrm{mL}$ and positive Anti GAD65 indicating a decrease in insulin secretion and autoantibodies from pancreatic cells indicating impaired insulin production in the pancreas. Islet Cell Antibody (ICA) examination was negative, there is only 1 positive antibody-antigen in this patient, Anti GAD65, so diagnosis Latent Autoimmune Diabetes in Adult (LADA) can be established in this patient.4-6,13,14

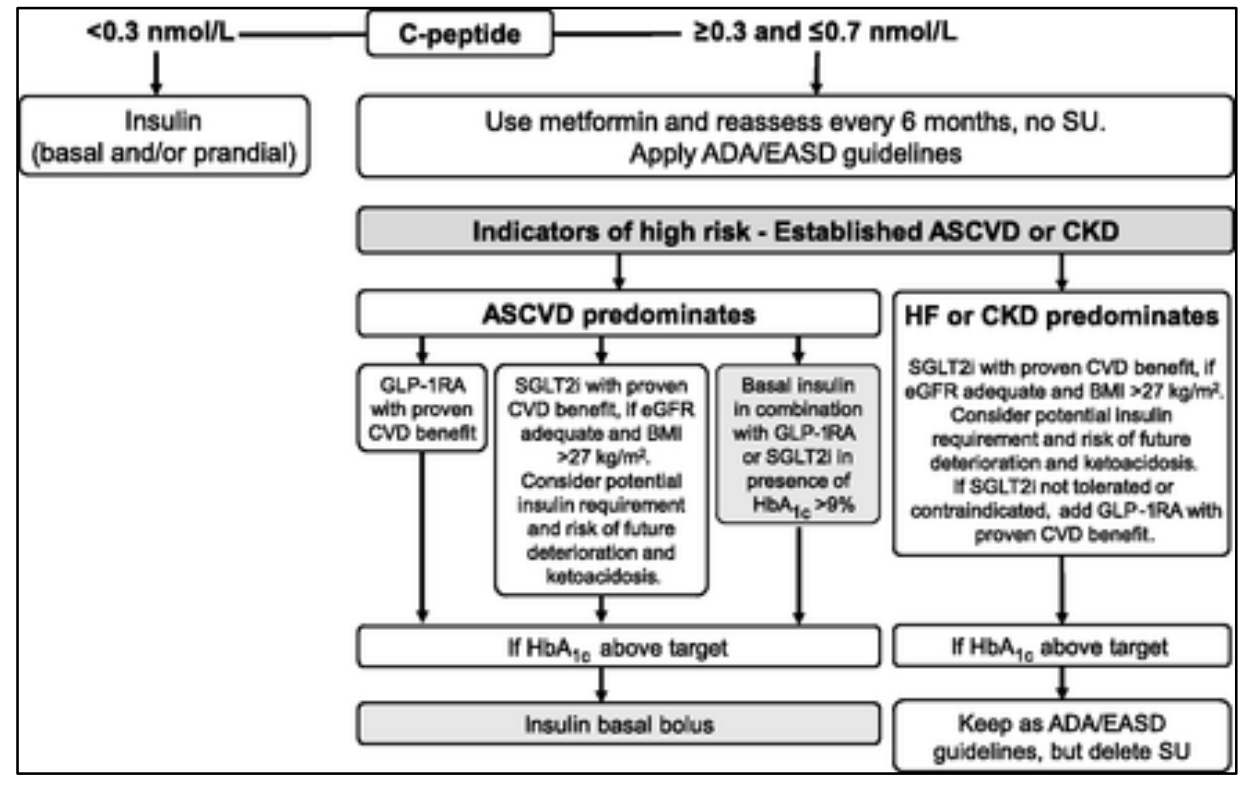

Figure 2. LADA management algorithm 5

Management in this patient is using insulin for a lifetime (insulin-dependent) and periodic evaluation of kidney function, liver function, and $\mathrm{Hb}-\mathrm{A} 1 \mathrm{C}$ levels to see whether the insulin dose given has reached the target or dose adjustment is needed to achieve $\mathrm{Hb}-\mathrm{A} 1 \mathrm{c}$ levels target and prevent organ damage resulting from prolonged and uncontrolled hyperglycemia 7

Diabetic ketoacidosis (DKA) is characterized by serum glucose levels greater than $250 \mathrm{mg}$ per $\mathrm{dL}, \mathrm{pH}$ less than 7.3, serum bicarbonate levels less than 18 $\mathrm{mEq} / \mathrm{L}$, elevated serum ketone levels, and dehydration. Insulin deficiency is a major precipitating factor. Diabetic ketoacidosis can occur at any age, with 14 percent of cases occurring in people older than 70 years, 23 percent in people 51 to 70 years old, 27 percent in people 30 to 50 years old, and 36 percent in younger people. than 30 years. The case fatality rate is 1 to 5 percent. Approximately one-third of all cases occur in people without a history of Diabetes mellitus (DM). ${ }^{8}$.
Insulin deficiency can stimulate an increase in counterregulatory hormones (glucagon, catecholamines, cortisol, and growth hormone). In cells that could not use glucose, the body will look for alternative energy sources. Increased lipase activity causes adipose tissue damage which produces free fatty acids. These components are converted to acetyl coenzyme A, some of which enter the Krebs cycle for energy production; and the others are broken down into ketones (acetone, acetoacetate, and $\beta$ hydroxybutyrate). Ketones can be used for energy, but they accumulate quickly. Glycogen and protein are catabolized into glucose. Together, these factors promote hyperglycemia, leading to an osmotic diuresis resulting in dehydration, metabolic acidosis, and a hyperosmolar state. ${ }^{8}$

Blood culture and urine culture were examined to find the source of infection, the results of urine culture with Candida tropicalis were obtained, so it can be concluded that this patient had diabetic ketoacidosis 
that was triggered by the presence of Sepsis caused by UTI.

Sepsis is the host systemic response to infection when a pathogen or toxin is released into the blood circulation resulting in activation of the inflammatory process. The pathophysiological sequence of sepsis is based on the occurrence of systemic inflammation involving various inflammatory mediators. The occurrence of disturbances in the coagulation system also plays an important role in the emergence of various complications caused by sepsis. Complications caused by sepsis can include systemic inflammatory response syndrome (SIRS), disseminated intravascular coagulopathy (DIC), septic shock, and multi-organ failure. 9

From history-taking, the patient had dysuria and fever since 1 week ago. On physical examination, sensorium was apathy, temperature $37.5 \mathrm{C}$, respiratory rate $28 \mathrm{x} /$ minute, pulse $100 \mathrm{x} /$ minute, on investigations, leukocytes $29,000 / \mu \mathrm{L}$, ureum 49 $\mathrm{mg} / \mathrm{dL}$, creatinine $2.52 \mathrm{mg} / \mathrm{dL}$, quantitative CRP 85.7 $\mathrm{mg} / \mathrm{L}$, blood gas analysis results PO2/FIO2: 84.1 $\mathrm{mmHg}$, urinalysis proteinuria, glucosuria, bacteriuria, ketonuria. Urine culture showed Candida tropicalis microbes.

From the data above, this patient was diagnosed with sepsis caused by UTI due to meeting the criteria for sepsis and qSOFA score of 2 and a SOFA score of 8 plus the suspicion of a focus infection. Selection of empiric antibiotics according to the site of infection i.e. Urinary Tract Infection (UTI) are 3rd generation cephalosporin, fluoroquinolones (ciprofloxacin and levofloxacin), beta-lactam/beta-lactamase inhibitor anti-Pseudomonas, and carbapenems with or without aminoglycosides. 10,11,12

Management of this patient is the administration of broad-spectrum antibiotics, Meropenem 2x1gr IV, and administration of antibiotics/antifungals according to the results of urine culture (Candida tropicalis), Mycafungin 1 x $150 \mathrm{mg} \mathrm{IV}$, and Fluconazole 2 x $150 \mathrm{mg}$ PO.

\section{Conclusion}

Diabetic ketoacidosis (DKA) in LADA caused by sepsis is an emergency in the field of metabolic endocrine and diabetes. Prompt and appropriate management can improve the prognosis in these cases.

\section{References}

1. WHO. Classification of diabetes mellitus. 2019; $14-35$

2. Holt, RIG, DeVries, JH, Hess-Fischl, A., Hirsch, IB, Kirkman, MS, Klupa, T., Ludwig, B., Nørgaard, K., Pettus, J., Renard, E., Skyler, JS, Snoek, FJ, Weinstock, RS, \& Peters, AL. The management of type 1 diabetes in adults. a consensus report by the American Diabetes Association (ADA) and the European Association for the Study of Diabetes (EASD). Diabetes Care. 2021. dci210043. https: / / doi.org/ 10.2337/dci21-0043

3. Family, A., \& Westerberg, DP. Diabetic ketoacidosis: Evaluation and treatment. 2013; 87(5). www.aafp.org/afp

4. Alvin C Powers. Diabetes mellitus, harrisons endocrinology 3rd edition. 261-275

5. Stenströ, G., Gottsä, A., Bakhtadze, E., Berger, B., \& Ran Sundkvist, G. Latent autoimmune diabetes in adults definition, prevalence,-cell function, and treatment. 2005.

6. Zimmet PZ, Tuomi T, Mackay IR, Rowley MJ, Knowles W, Cohen M, Lang DA: Latent autoimmune diabetes mellitus in adults (LADA): the role of antibodies to glutamic acid decarboxylase in diagnosis and prediction of insulin dependency. Diabetes Med11: 1994; $299-303$

7. Mobasseri M, Shirmohammadi M, Amiri T, Vahed N, Hosseini Fard H, Ghojazadeh M. Prevalence and incidence of type 1 diabetes in the world: a systematic review and metaanalysis. Health Promote Perspect 2020; 10: 98-115

8. Family, A., \& Westerberg, DP. Diabetic ketoacidosis: Evaluation and treatment. 2013; 87(5). www.aafp.org/afp

9. Dellinger RP, Levy M, Carlet JM, Bion J, Parker MM, Jaeschke $R$, et al. Surviving sepsis campaign: international guidelines for management of severe sepsis and septic shock: 
2008. Crit Care Med. 2008; 36: 296-327.

10. Martin GS, Mannino D, Eaton S, Moss M. The epidemiology of sepsis in the United States from 1979 through 2000. N Engl J Med. 2003; 348: 1546-54.

11. Sarhan M, von Mässenhausen A, Hugo C, Oberbauer R, Linkermann A. Immunological consequences of kidney cell death. Cell Death Dis. 2018 Jan 25; 9(2): 114.

12. Kodner CM, Thomas Gupton EK. Recurrent urinary tract infections in women: diagnosis and management. Am Fam Physicians. 2010 Sep 15; 82(6): 638-43.

13. Ride RG, Brooks-Worrell BM, Palmer JP. Latent Autoimmune Diabetes in Adults. J Clin Endocrinol Metab 2009; 94(12): 4635-44

14. Behme MT, Dupre J, Harris SB, Hramiak IM, Mahon JL. Insulin resistance in latent autoimmune diabetes of adulthood. Ann NY Academy of Science 2003; 1005: 374-7. 